\title{
Fatigue and creep analyses of adhesively bonded anchorages for CFRP tendons
}

\author{
F. Puigvert ${ }^{\mathrm{b}}$, A.D. Crocombe ${ }^{* a}$, L. Gil $^{\mathrm{b}}$

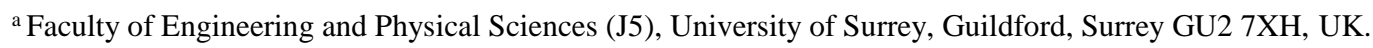 \\ ${ }^{\mathrm{b}}$ Department of Strength of Materials and Structural Engineering (RMEE), Polytechnic University of Catalonia, \\ Terrassa, 08222, Spain.
}

\begin{abstract}
A bonded anchorage was investigated where a CFRP tendon was potted in a steel tube using an epoxy adhesive. Experimental creep tests on single lap joints and fatigue tests on anchorages, both with different adhesive thickness, were undertaken with failure occurring in the bond, close to the CFRP interface in both cases. The creep and fatigue response of the adhesively bonded CFRP tendon anchors were separately predicted using Finite Element analysis. A visco-plastic material model was used to predict the time to failure of the anchors in creep. The effect of creep damage was modelled by degrading the yield stress of the adhesive. Moreover, a bi-linear traction-separation cohesive zone model was incorporated at the adhesive-tendon interface when simulating the fatigue loading of the anchorages. A fatigue damage model based on the degradation of the cohesive elements was implemented to take into account the fatigue damage evolution. The predicted results were found to be in good agreement with the experimentally recorded data.
\end{abstract}

Keywords: finite element stress analysis, creep, fatigue, cohesive zone model.

\section{Introduction}

\footnotetext{
${ }^{*}$ Corresponding author. Tel.: +44-1483-689-194;.

E-mail address: a.crocombe@surrey.ac.uk (A.D. Crocombe).
} 
In pre-stressed concrete structures subjected to corrosive environments, CFRP tendons are being considered as replacements for steel tendons. There are basically two main anchor systems used to attach the tendon of composite material to the structure: mechanical anchors and adhesively bonded anchors. The first is based on the current anchors for steel tendons and is not considered entirely successful because the wedges tend to dig into the composite material causing premature failure. The bonded anchor is considered more efficient for composite materials as the stress distribution on the interface is more uniform. For this reason, adhesively bonded anchorages are being investigated to attach composite material tendons to the anchor structure. An adhesive bond-type anchorage consists of a steel housing inside which single or multiple tendons are bonded with an adhesive. These joints are increasingly being utilised because of their recognised advantages over the mechanical anchorages. The overall properties of a bond-type anchorage depend mainly on the geometry of the materials involved in the joint and the properties of the adhesive.

Bonded anchorages have been studied by many researchers under quasi-static loading [1-4]. Most of them have observed, through experimental tests, that the failure occurs in the bond line between the composite material and the adhesive before reaching the maximum strength of the composite material. Nevertheless, little attention has been paid to the creep and fatigue response of the potted anchor.

Moreover, creep and fatigue loading add a level of complexity when considering causes of damage in mechanical structures. Although fatigue is a phenomenon associated with metals, it is also present in polymers and ceramic materials. Most composite materials are also sensitive to cyclic fatigue loads, which can lead to premature failure. Fatigue failure in composite materials arises from different damage mechanisms that appear in different zones of the material throughout its life. The combination of these local damages causes the degradation of the 
mechanical properties globally [5]. Although composite materials may exhibit a reasonable fatigue performance, the major concern in this work lies in the adhesive bond [6].

Adhesively bonded joints under fatigue load have been mainly studied through single lap joints (SLJs), double lap joints (DLJs) and laminated doublers in bending (LDB) [6-13]. Usually, experimental tests are combined with predictive numerical models in order to reduce the time and cost of the final design. The typical variables assessed are the maximum fatigue load, the load ratio $(R)$ and the frequency. In the present work, the maximum fatigue load and the load ratio were determined from the usual stress levels of these anchors for steel tendons. The effect of the maximum fatigue load and the load ratio generally determine the fatigue response of adhesively bonded joints, whilst the loading frequency is often less important, as mentioned by Crocombe et al. [7].

Different methods have been employed to model the fatigue damage in adhesive joints based on the stress singularity or on fracture mechanics. These methods predict the lifespan of the joint taking into account either the damage initiation or the damage propagation $[7-9,14,15]$. The cohesive zone model (CZM) has recently been considered for predicting the fatigue response where the crack path is known in advance. The cohesive elements combine damage initiation (once the cohesive elements reach the maximum traction allowed) and damage propagation (that can be defined as a function of the fracture energy or the displacement at failure).

Some authors $[16,17]$ have modelled fatigue loading using cohesive elements with a damage evolution equation which was evaluated cycle by cycle. This was computationally very expensive and limited to low cycle fatigue. More recently, the fatigue damage response of adhesively bonded joints has been modelled using cohesive elements with progressive fatigue damage based on the maximum fatigue load and load ratio degrading the parameters of the cohesive elements [10-12]. The damage evolution law was assessed for blocks of cycles. This allows efficient use of computing resources and can simulate high cycle fatigue. For each block 
of cycles, the cohesive element properties were degraded following a cyclic fatigue damage evolution law. These parameters were calibrated against experimental data.

On the other hand, creep is also considered to be one of the challenges associated with these systems. As with fatigue loading, the weakest part of the system often lies in the bonded joint. Regarding the composite material, Yamaguchi et al. [18] conducted creep tests with GFRP, CFRP and AFRP tendons. The bars were tested experimentally at different loads. The results indicated that there was a linear relationship between creep stress and the logarithm of the time to failure. Through a linear extrapolation, it was shown that it was possible to stress CFRP tendons over $80 \%$ of their ultimate tensile strength to obtain a lifespan of over 50 years.

However, the bonded joint is more sensitive to suffering premature failure caused by creep than the CFRP tendon.Many models $[19,20]$ have been developed in order to understand the behaviour of bonded joints at high or low temperatures. The objective of these investigations was to study the stress distribution in adhesive joints to find the best possible design at these temperatures. Su and Mackie [21] developed a two dimensional finite element program to simulate the creep phenomenon in adhesively bonded joints. A visco-plastic model was used for the adhesive and the creep was modelled by reducing the plastic yield stress to zero. When the specimen was analysed, a peak was observed in normal and shear stress distributions along the bond line. Creep led to a more even distribution of the stresses, reducing these peaks, and the strains showed a large increase with time.

Even though creep and fatigue have been studied in adhesively bonded joints, there is still a lack of knowledge of these phenomena relating to potted anchors. In the present work, constant amplitude fatigue loads with high load ratios $(R)$ were applied to adhesively bonded anchorages for CFRP tendons. As the load ratio is high the adhesive may experience creep as well as fatigue damage. This is a complex situation and the approach adopted here has been to consider the creep and fatigue damage aspects separately. Both the experimental and the modelling sections 
contain separate sections for each type of loading. The creep response of the adhesive was assessed experimentally using SLJs under sustained constant loading while the potted anchors were assessed experimentally under high load ratio fatigue loading. The experimental SLJ creep tests provided a creep power law which was used to simulate the creep deformation that the potted anchors might experience in the high load ratio fatigue loading. This was achieved by applying a creep load equal to the mean fatigue load to the FE model of the anchors. The viscoplastic model was implemented in ABAQUS. In order to include progressive damage leading to creep failure the creep strains were used to degrade the adhesive yield stress, thus leading to local failure when a given creep strain was reached. By applying this creep model to the anchor it was found that the predicted times to failure under creep were generally sufficiently long that, in the first instance, the creep aspects need not be considered in the fatigue loading of the anchors. Then, following the method used by Crocombe et al. [12], the fatigue was modelled using a cohesive zone model to simulate the deleterious influence of the fatigue loading on the bonded joints. A user subroutine was written to degrade the properties of the cohesive elements according to a fatigue damage evolution equation. The predicted results were found to be in good agreement with the experimental data.

\section{Experimental work}

\subsection{Materials and methods}

Two different types of adhesively bonded joints, namely single lap joints (SLJs) and anchors were tested under creep and fatigue loading, respectively. The carbon fibre/epoxy laminate plates used in this study for the SLJs and the anchor rods were manufactured using a pultrusion process. Failure in the potted anchor occurred adjacent to the adhesive-CFRP interface. Thus to increase the likelihood of failure in the same location both substrates in the SLJ were CFRP. The CFRP material was MBrace Laminate LM [22] for the SLJs and MBar Galileo [23] for the anchors. The contents of fibre and resin for both composite materials were $65 \%$ and $35 \%$ by 
volume, respectively. The composite materials were provided with a peel ply that was removed immediately prior to bonding. No other preparation in the CFRP laminates and rods was required. In addition, the CFRP laminates and rods had shallow depressions on the surface in order to optimise the bond with the adhesive. The tensile strength of the CFRP laminates and rods were $2500 \mathrm{MPa}$ and the modulus of elasticity $140 \mathrm{GPa}$. The adhesive used was MBrace Primer [24], a low viscosity polyamine cured epoxy. The modulus of elasticity of the adhesive was $700 \mathrm{MPa}$. The tensile and compressive yield stresses are 14.5 and 26.2 MPa respectively. All the components were manufactured by BASF Chemical Company.

The low viscosity of the adhesive usually enables an easy preparation of the joints avoiding air cavities and undesirable imperfections. This allows manufacture of the joints by pouring the adhesive into the overlap region unlike adhesives with high viscosity which require a more complex procedure.

For SLJs, the CFRP laminates were placed edge-on on a glass plate and square end spacers were used to make up the SLJs with no fillets. With the joint configured appropriately, a thermoplastic glue gun was utilised to seal all the sides of the overlap except the upper face. This formed a cavity into which the adhesive was poured. On cure the thermoplastic sealant and end spacers were easily removed.

For the anchorages, the CFRP rods were potted in the steel housings using the same epoxy resin as used in the SLJs. The inner surface of the steel housing was cleaned using acetone to remove any impurities before inserting the tendon. Small centring pieces were placed at both ends of the anchor to locate the FRP rod in the correct position. The bottom of the anchor was sealed with a thermoplastic sealant to avoid leaks. Once the sealant was totally cured, after approximately 30 min., the spacers and centring pieces were removed and the joint dimensions were checked. If the dimensions were not suitable, the procedure was repeated. 
Finally, the adhesive was prepared with a mechanical mixer and poured into the gap between the tendon and the inner bore of the anchor. The application of the adhesive was carried out slowly to avoid the formation of voids or gaps in the bond layer..

All the specimens were cured at room temperature, according to the specifications of the adhesive manufacturer. Standard laboratory conditions were assured during all bonding processes and testing activities. This includes a temperature of $23 \pm 2^{\circ} \mathrm{C}$ and a relative humidity of $50 \pm 5 \%$.

\subsubsection{SLJ test setup}

To determine appropriate levels of creep loading, tests on SLJs were undertaken to determine the static strength. The static tests were carried out using an MTS actuator under displacement control at $0.5 \mathrm{~mm} / \mathrm{min}$. Force and displacement were recorded at a frequency of $50 \mathrm{~Hz}$ using an HBM MGCPlus data acquisition system. The SLJs were a standard single lap joint following ASTM D3165 [25]. The dimensions of the SLJs are shown in Fig. 1. The overlap length, the width and thickness of the bond line are summarised in Table 1. One specimen of each geometry was tested to failure in order to obtain the static strength. As can be seen the parameter varied was the adhesive thickness. This was because in the anchor system different thicknesses of adhesive were being evaluated. The overlap length was not varied in the SLJs as in the anchor system the overlap length is sufficiently long to allow the full load transfer to take effect.

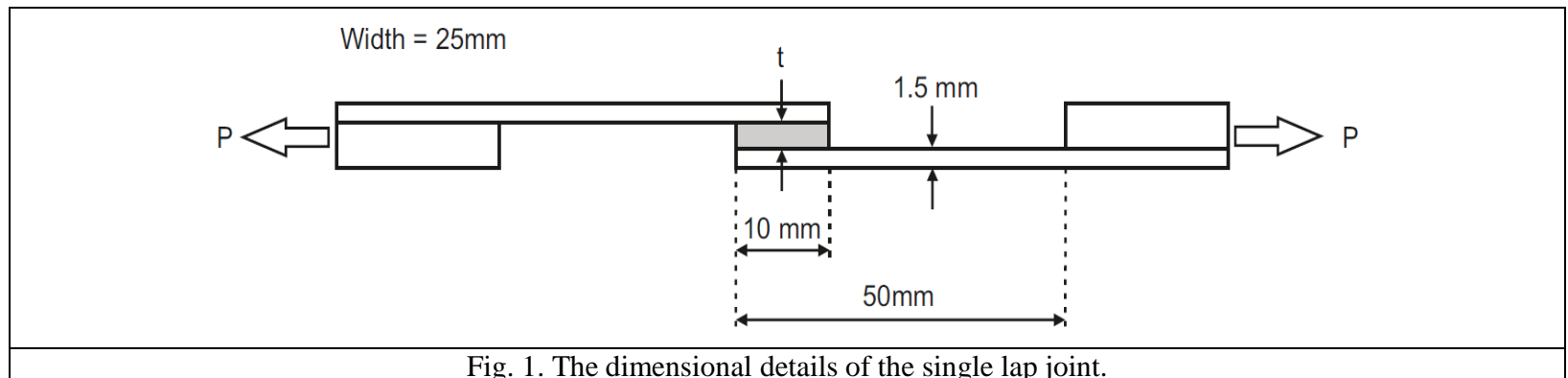

Fig. 1. The dimensional details of the single lap joint.

\begin{tabular}{|cccc|}
\hline \multicolumn{4}{|c|}{ Table 1. Geometric characteristics of SLJ. } \\
\hline Specimen & $\begin{array}{c}\text { Length } \\
\text { L[mm] }\end{array}$ & $\begin{array}{c}\text { Width } \\
{[\mathrm{mm}]}\end{array}$ & $\begin{array}{c}\text { Thickness } \\
\mathrm{t}[\mathrm{mm}]\end{array}$ \\
\hline SLJ_1.6mm & 10 & 25 & 1.6 \\
\hline
\end{tabular}




$\begin{array}{llll}\text { SLJ_3.2mm } & 10 & 25 & 3.2 \\ \text { SLJ_4.8mm } & 10 & 25 & 4.8 \\ \text { SLJ_6.4mm } & 10 & 25 & 6.4\end{array}$

Creep tests on the SLJs based on ASTM D2294 [26] were then undertaken. The creep test machine was based on a levered beam with a load ratio of 10:1, as seen in Fig. 2. SLJs were attached to the shorter arm of the beam and the specimens were aligned vertically to avoid unwanted bending effects. The load was applied to the specimen through a dead weight applied at the other end of the beam. It was applied by hand gradually over a short timespan to avoid any sharp impulse on the beam. The load remained constant after application until failure of the specimen. The use of a levered beam test setup is a well-known technique for creep testing [27]. Time to failure was recorded using an HBM Spider 8 acquisition system. When the specimen failed, the loading weight on the other side of the beam fell on an aluminium plate. This plate was instrumented with a strain gage and the values of strain were continuously recorded at a low frequency $(1 \mathrm{~Hz})$. When the loading weight fell, a large jump in the strain was recorded. This enabled the time when the specimen failed to be accurately determined. The creep test setup for the SLJs is shown in Fig. 2. The different loads assessed were the 80, 60 and $40 \%$ of the average static strength for all the geometries and an additional load of $20 \%$ of the average static strength was used for the joint SLJ_3.2mm.

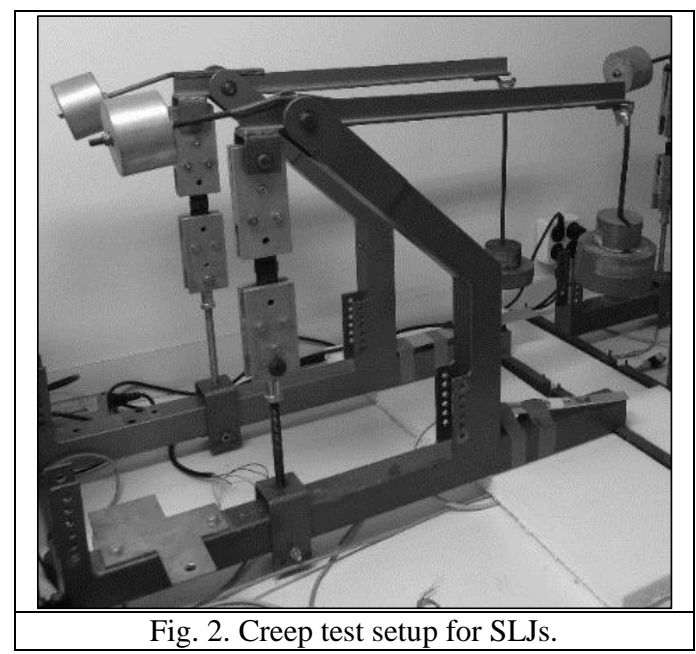

\subsubsection{Anchor test setup}


In order to normalise the fatigue experimental results from the different anchor geometries, the static strength of the anchorages was required. Before fatigue testing, static tests were conducted on the anchors with the maximum and minimum adhesive thickness. The geometric characteristics of the anchors are summarised in Fig. 3 and Table 2. The static tests were carried out using an MTS actuator under displacement control at $1 \mathrm{~mm} / \mathrm{min}$. Force and displacement were recorded at a frequency of $50 \mathrm{~Hz}$ using an HBM MGCPlus data acquisition system.

Fatigue tests on the anchor joints were carried out using an MTS actuator at a loading frequency of $4 \mathrm{~Hz}$. The number of cycles, load, displacement and time were recorded at a frequency of 100 $\mathrm{Hz}$ using an MGCPlus acquisition system. The fatigue test setup is shown in the Fig. 4. The different loads assessed are summarised in Table 3.

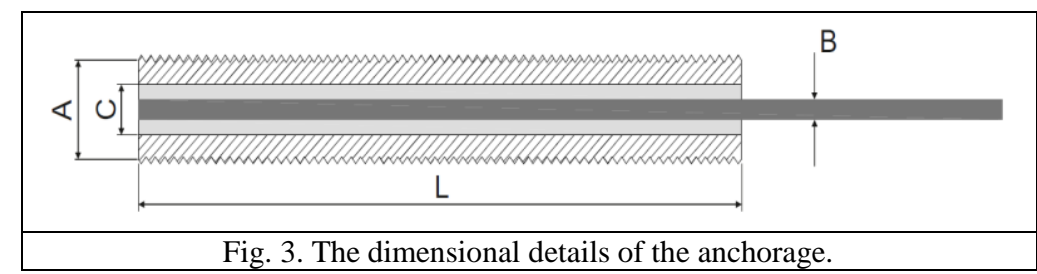

\begin{tabular}{|ccccc|}
\hline \multicolumn{5}{|c|}{ Table 2. Geometric characteristics of anchorage. } \\
\hline Specimen & $\begin{array}{c}\text { Steel tube } \\
\text { outer diameter } \\
\text { A [mm] }\end{array}$ & $\begin{array}{c}\text { CFRP rod } \\
\text { diameter, B } \\
{[\mathrm{mm}]}\end{array}$ & $\begin{array}{c}\text { Steel tube } \\
\text { bore, C } \\
{[\mathrm{mm}]}\end{array}$ & $\begin{array}{c}\text { Anchor } \\
\text { length, L } \\
{[\mathrm{mm}]}\end{array}$ \\
\hline DIA_14_200mm & 26 & 8 & 14 & 200 \\
DIA_16_200mm & 26 & 8 & 16 & 200 \\
DIA_18_200mm & 26 & 8 & 18 & 200 \\
DIA_20_200mm & 26 & 8 & 20 & 200 \\
\hline
\end{tabular}

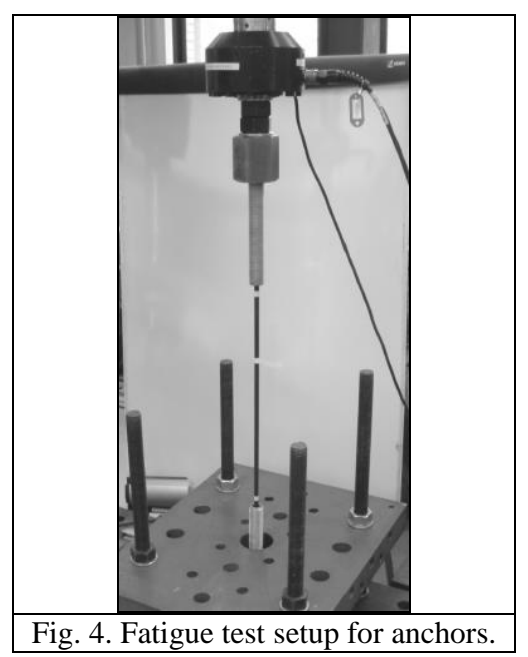




\begin{tabular}{|llll|}
\hline \multicolumn{4}{|c|}{ Table 3. Fatigue loading spectra conditions. } \\
\hline $\begin{array}{l}\text { Fatigue loading } \\
\text { spectra }\end{array}$ & $R=P_{\min } / P_{\max }$ & $\begin{array}{l}P_{\operatorname{mean}} \\
{[\mathrm{kN}]}\end{array}$ & $\begin{array}{l}P_{\max } \\
{[\mathrm{kN}]}\end{array}$ \\
\hline A & 0.84 & 36 & 39 \\
B & 0.77 & 24 & 27 \\
C & 0.92 & 24 & 25 \\
\hline
\end{tabular}

\subsection{Testing results}

\subsubsection{SLJ testing results}

In all the SLJs tested under static and creep loading the failure occurred in the adhesive but very close to the interface between the adhesive and the composite material. Fig. 5 shows a typical failure surface in the overlap region for the SLJs.

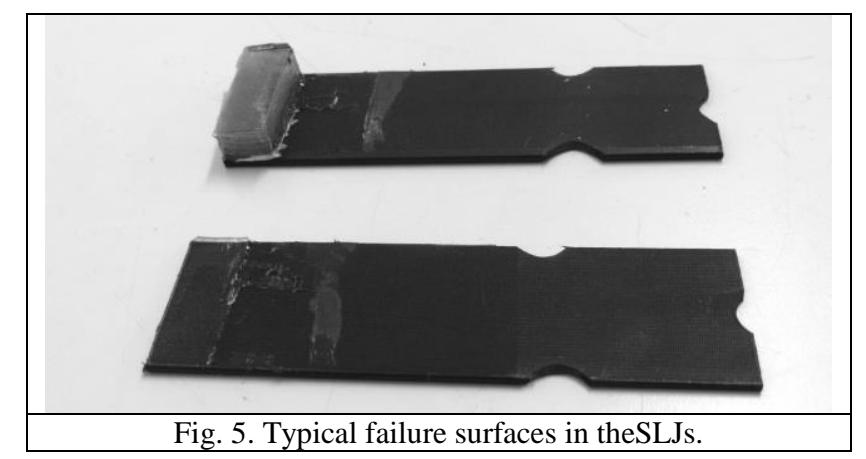

In the static tests, the experimental force-displacement curves were largely linear up to the point of failure, which occurred suddenly. The average static strength obtained of all four specimens was $1.563 \mathrm{kN}$. This value was used to determine the creep loads which were 1250, 940, 625 and $325 \mathrm{~N}$ representing $80,60,40$ and $20 \%$ of the average static strength of SLJs respectively.

The experimental creep times to failure obtained from the single lap joints are shown in Fig. 6 . Clearly, the average shear stress is the same for all the specimens which were loaded with the same load. Generally, the increased load eccentricity associated with the thicker adhesive layers introduced an increased bending moment and hence increased the adhesive stresses. This resulted in the thicker specimens tending to have a shorter lifetime than the thinner specimens at the same creep load. However, as there was not a clear trend for the individual geometries, the experimental data were combined into one curve, giving the relation between the average shear stress and the time to failure. As the average stress was reduced, the lifespan was increased. In 
this approach, the effect of adhesive thickness will be accommodated by introducing a thickness dependent creep failure strain, as discussed later. 


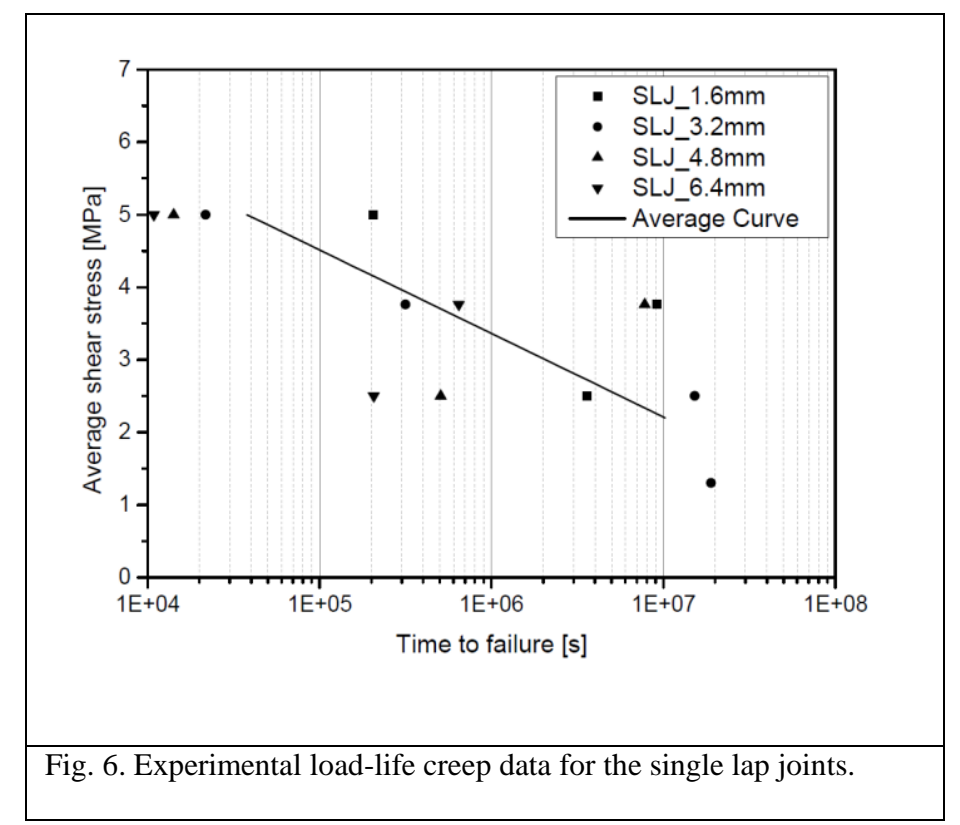

\subsubsection{Anchor testing results}

As mentioned earlier the static strength of the anchorages is required to normalise the fatigue data. Static tests up to failure were conducted and static strengths of 39.95 and $51.15 \mathrm{kN}$ were obtained for the thinnest and thickest adhesive layers, respectively. From these values, a linear interpolation was applied between the adhesive thickness and experimental static strength obtained to determine the static strength of the rest of the geometries, as in previous research [4]. The force-displacement curves of these specimens are shown in Fig. 7. It can be seen that the specimens behaved mostly linear up to instantaneous failure.

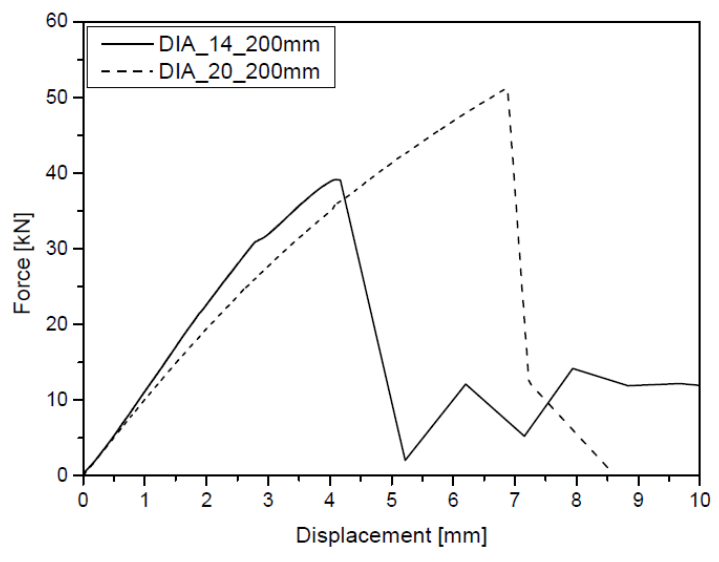


Fig. 7. Measured load-displacement response of anchorages with the thinnest and thickest adhesive thickness tested under static loading up to failure.

In all the bonded anchorages under static and fatigue loading, the failure occurred in the adhesive but very close to the adhesive-rod interface. Fig. 8 shows the typical failure surface throughout the bond length for the anchorages.

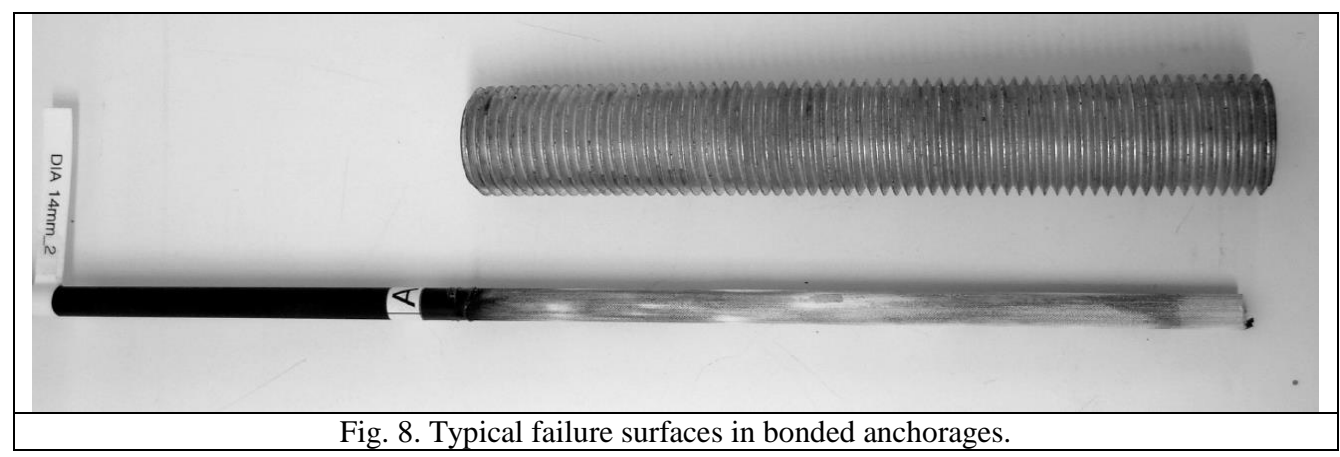

The fatigue results are plotted in Fig. 9. The maximum fatigue load, $P_{\max }$, has been plotted against the number of cycles to failure. From the experimental fatigue test results of the anchors it was observed that the specimens with a higher adhesive thickness generally achieved a higher number of cycles to failure. This is probably due to the fact that the thicker adhesive layers produced a more uniform distribution of adhesive stress along the bonded anchor. It is worth noting that three specimens, marked with arrows in the figure, did not reach failure by the end of the fatigue test. The case with the lowest cycles was due to a clamping system failure halting the test and the other two because the maximum number of cycles $\left(1 \times 10^{6}\right)$ had been reached. These "unfailed" joints were not considered in determining the trend curves for the fatigue load-life data. 


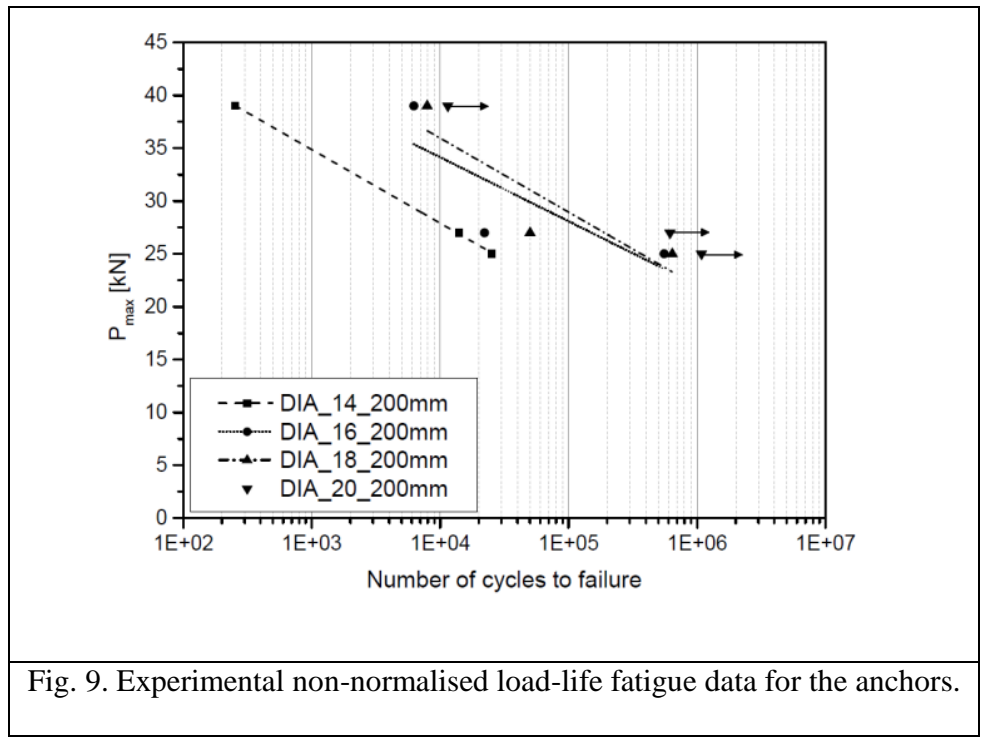

The normalised fatigue results are plotted in Figs. 10 and 11. The first figure shows the fatigue life plotted against the maximum fatigue load, $P_{\max }$, of the anchors, normalised by the static failure load, $P_{s}$. The latter shows the fatigue life plotted against the loading range, $\Delta P$, normalised by the static failure load. As can be observed, when the fatigue loading was defined by the maximum fatigue load (Fig. 10), the experimental data dispersion was much lower than when using the loading range (Fig. 11). This suggests the maximum load may be the most appropriate way of characterising the fatigue loading applied here.

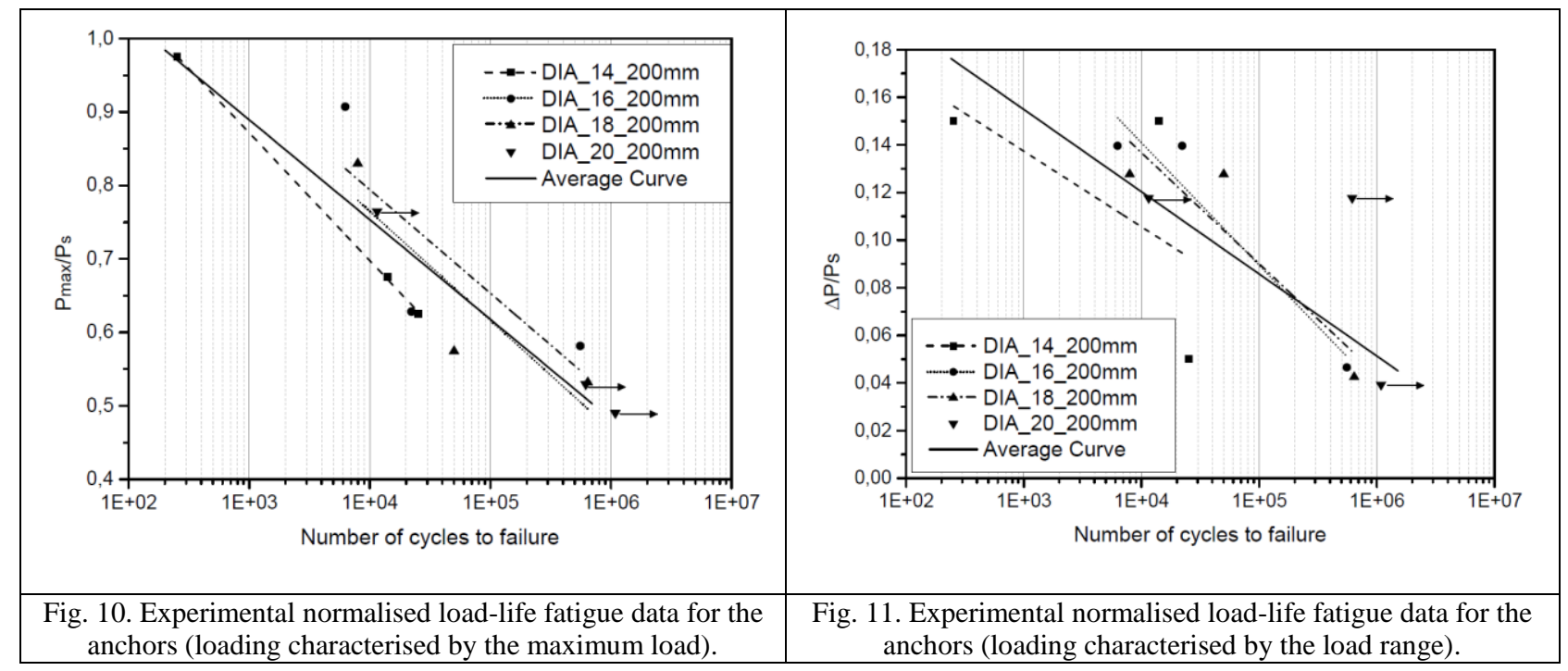

2.3 Failure surface analysis 
Failure surface analyses were conducted on SLJs and bonded anchorages using a stereoscopic microscope SCZ-T4P Carton with magnification levels ranging from 10x to 25x. Pictures of the failure surface were obtained with a USB Microscope camera Deltapix DP300.

The conventional naked-eye examination after failure shown in Figs. 5 and 8, revealed that the failure in all specimens was produced on the adhesive but very close to the adhesive-CFRP substrate interface. This failure mode was confirmed with the microscopic analysis, where the CFRP laminates and rods examined were impregnated with a small layer of adhesive. These surfaces also contained adhesive particles due to local cohesive failure of the adhesive.

Fig. 12 shows the CFRP laminate failure surface of the specimen SLJ_6.4mm_1 which was considered representative of most SLJs. The failure surface was very close to the adhesivesubstrate interface where the laminate surface roughness largely remained complete. It can be also seen that the layer of adhesive impregnated on the laminate was very thin and thus the braided surface of the composite material is visible.

Moreover, the conventional naked-eye examination on SLJs occasionally detected different local failure modes worth mentioning. Fig. 13 shows a local failure surface of the adhesive where the cohesive failure of the adhesive was more evident, especially at the top of the image. Further, Fig. 14 shows the adhesive layer surface where the epoxy resin acquired the shape of the shallow hollows of the composite material and, locally, some particles of the CFRP laminate were attached to the adhesive layer.

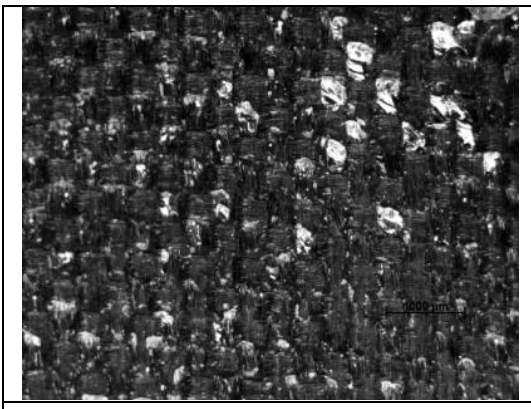

Fig. 12. CFRP laminate failure surface of specimen SLJ_6.4mm_1 magnified $\mathrm{x} 10$.

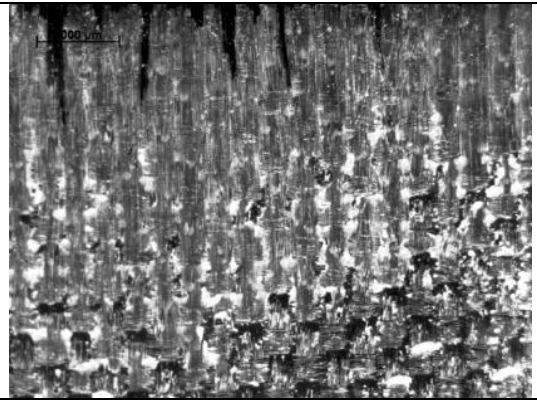

Fig. 13. Adhesive failure surface of specimen SLJ_6.4mm_2 magnified x10.

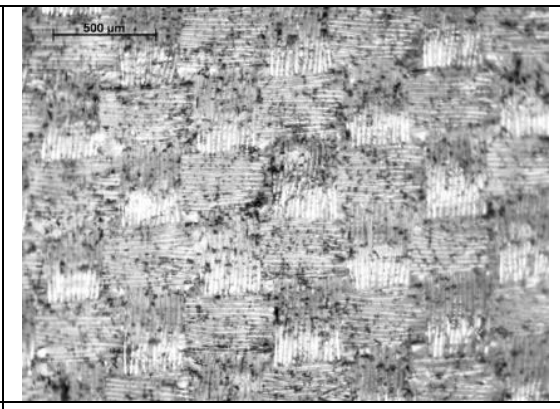

Fig. 14. Adhesive failure surface of specimen SLJ_1.6mm_1 magnified x25. 
Furthermore, Figs. 15 and 16 show the CFRP rod failure surface of the anchor

DIA_14_200mm_3 magnified at x10 and x25, respectively. This failure surface was

representative of most of the bonded anchorages tested under fatigue loading. As can be seen, the nature of the adhesive damage is similar to the SLJ failure surfaces. This result justifies using the experimental data from the SLJs in order to predict the time-dependent behaviour of the bonded anchorages.

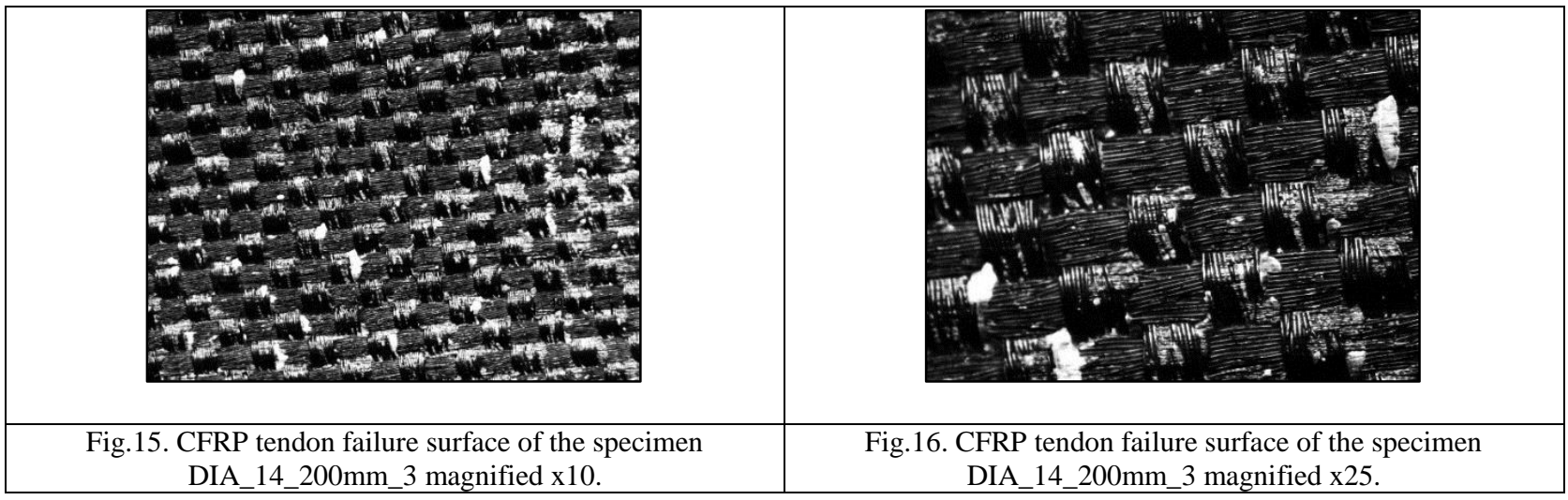

\section{Finite element modelling}

Finite element models were developed in Abaqus/CAE for SLJs and anchors in order to predict the creep and fatigue response of the anchors. First, a 2D plane stress finite element model, shown in Fig. 17, was developed to predict the SLJ behaviour under creep loading. Four different geometries were modelled according to the geometries tested experimentally (see Table 1). Four-noded plane stress elements (CPS4R) with a mesh density of $0.1 \mathrm{~mm}$ were used for the whole model. A mesh size of $0.1 \mathrm{~mm}$ was required for the adhesive as this matched the mesh size used in the anchor creep modelling. This level of refinement in the substrates was not strictly necessary but was used purely for ease of mesh generation. One end of the substrate was assigned an encastre constraint. At the other end the transverse displacement and the rotation were constrained and the (axial) creep load was applied. 


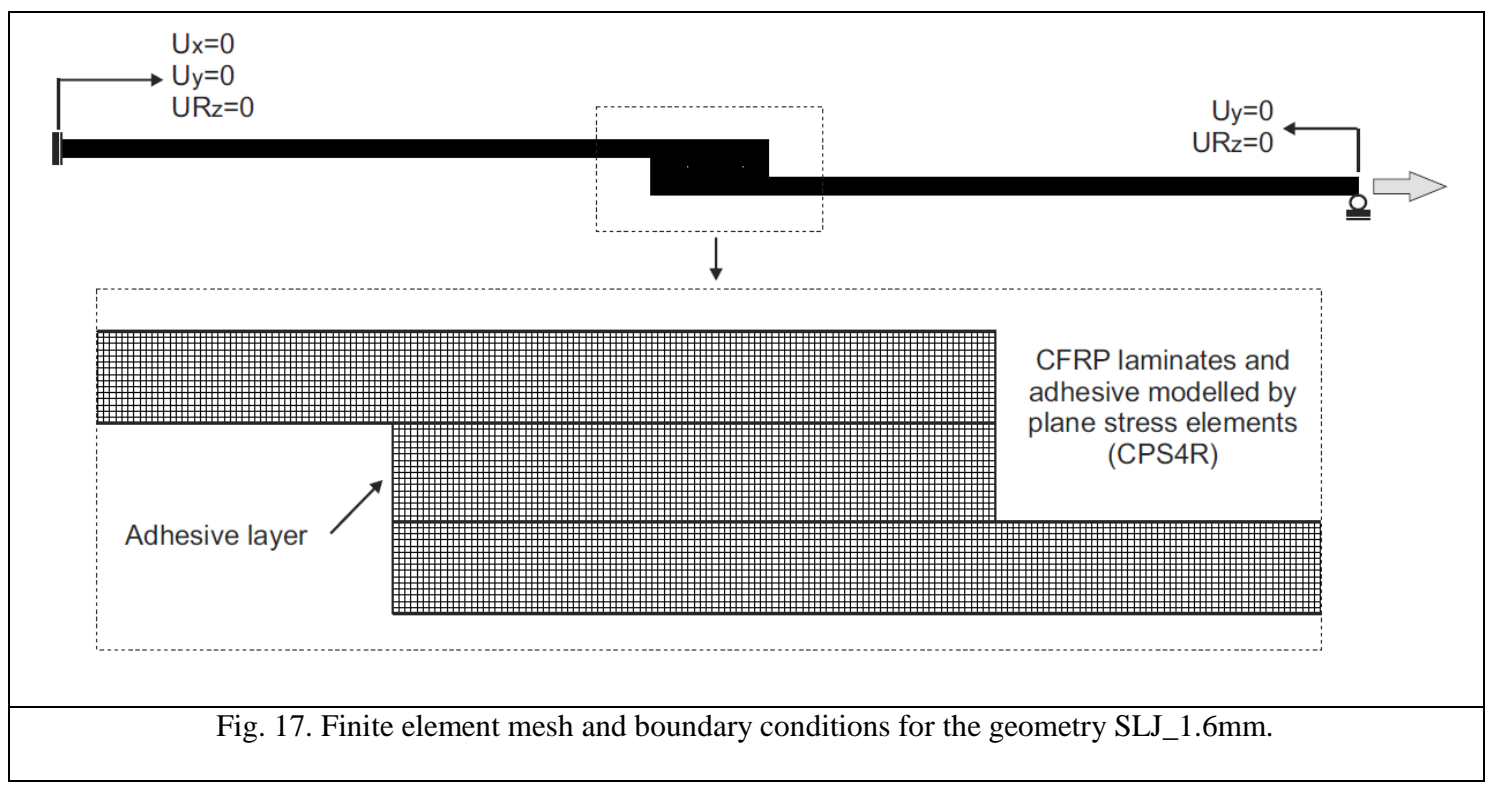

On the other hand, a 2D axisymmetric model was developed for the anchor (see Fig. 18). An axisymmetric model, rather than a full 3D model, was considered to minimise the computational effort. The geometries tested experimentally were modelled, see Table 2 . The bottom of the steel housing was entirely fixed and the top of the CFRP was loaded with an axial force. The anchor models were used to simulate the effect of both creep and fatigue loading. Four-noded axisymmetric stress elements (CAX4R) with a mesh density of $0.1 \mathrm{~mm}$ ( as in the SLJs) were used for the creep model.. Even though the mesh produced is, possibly, excessively fine, the same mesh was required because the maximum creep strain from the SLJs simulations were taken to determine the creep failure time of the anchors. This is more valid if the meshes are the same size in both cases.

Four-noded axisymmetric stress elements (CAX4R) with a mesh density of $0.5 \mathrm{~mm}$ were used for the fatigue model, where there was no requirement to have the same mesh size as the SLJ model. In the fatigue models a cohesive layer was used adjacent to the adhesive-rod interface as it was found from the experimental observations that the failure always occurred in this adhesive-rod interface region. Four-node axisymmetric cohesive elements (COHAX4) with a bi-linear traction-separation response were utilised to study the progressive damage in the adhesive bond 
line. The size of the cohesive element was $0.5 \times 0.5 \mathrm{~mm}$ along the entire adhesive bond line.

Geometric non-linearity was included in all the analyses.

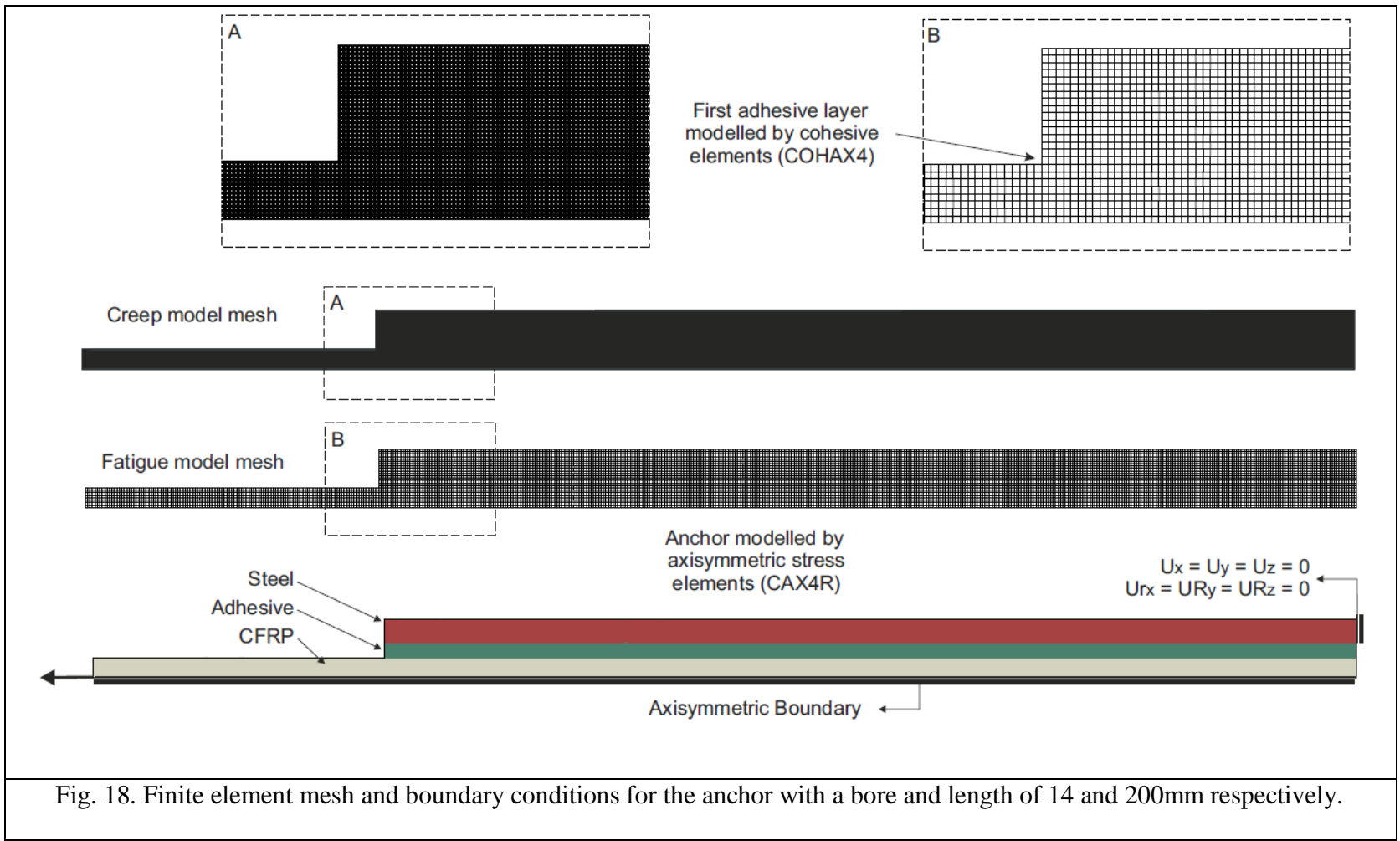

\begin{tabular}{|c|c|c|c|c|c|c|c|c|}
\hline \multicolumn{4}{|c|}{$\begin{array}{l}\text { Table } 4 . \text { Mechanical properties of the materials } \\
\text { involved in the numerical modelling. }\end{array}$} & \multicolumn{5}{|c|}{ Table 5. Tensile and compressive data of the bulk adhesive. } \\
\hline Parameters & $\begin{array}{l}\begin{array}{l}\text { Steel } \\
\text { tube }\end{array} \\
\end{array}$ & $\begin{array}{c}\text { CFRP } \\
\text { rod/laminate }\end{array}$ & Adhesive & Properties & $\begin{array}{c}\text { Yield } \\
\text { strength } \\
{[\mathrm{MPa}]}\end{array}$ & $\begin{array}{c}\text { Strain } \\
\text { at yield } \\
{[\%]}\end{array}$ & $\begin{array}{c}\text { Ultimate } \\
\text { Strength } \\
{[\mathrm{MPa}]}\end{array}$ & $\begin{array}{c}\text { Rupture } \\
\text { strain } \\
{[\%]} \\
\end{array}$ \\
\hline $\begin{array}{c}v[-] \\
\mathrm{E}[\mathrm{MPa}]\end{array}$ & $\begin{array}{c}0.3 \\
200,000\end{array}$ & $\begin{array}{c}0.2 \\
141,000\end{array}$ & $\begin{array}{c}0.425 \\
700\end{array}$ & Tensile & $\frac{[\mathrm{MPa}]}{14.5}$ & $\begin{array}{c}{[\%]} \\
2.0\end{array}$ & {$\left[\begin{array}{l}{[\mathrm{MIF} \mathrm{a}]} \\
17.2\end{array}\right.$} & $\begin{array}{c}{[70]} \\
40\end{array}$ \\
\hline & & & & Compressive & 26.2 & 4.0 & 28.3 & 10 \\
\hline
\end{tabular}

\begin{tabular}{|cc|}
\hline \multicolumn{2}{|c|}{ Table 6. Creep power law parameters. } \\
\hline $\begin{array}{c}\text { Power law } \\
\text { multiplier, A }\end{array}$ & $\begin{array}{c}\text { Eq. Stress } \\
\text { order, B }\end{array}$ \\
\hline $1.75 \mathrm{E}-013$ & 7 \\
\hline
\end{tabular}

\subsection{Creep modelling}

The creep modelling of both joints (SLJs and anchors) were conducted considering elasticperfectly plastic von Mises plasticity, creep and progressive damage for the adhesive. An elasticperfectly plastic model was deemed a reasonable starting point for two reasons a) the post-yield hardening is relatively modest and b) the elastic-plastic model parameters are to be degraded by the accumulated creep strain and so the exact form of plasticity is not as critical as an analysis where the plasticity is not degraded. A rate-dependent analysis was required to consider the 
creep phenomenon. As can be seen in Fig. 19a, two steps were applied. In the first step, the force was applied linearly from 0 to $P_{\max }$ in 1 second. In the second, much longer, step the force remained constant until the creep failure of the joint was reached. In the SLJs, $P_{\max }$ was based on the experimental loads used. As there was no experimental creep testing of the anchors, the forces used in the anchor modelling were the mean force applied in the experimental fatigue tests. This anchor modelling was undertaken in order to assess whether the predicted creep time to failure were sufficiently long that creep damage could be neglected, when compared with the fatigue damage, in the fatigue modelling. Although the anchor and the SLJ do not experience the same mode mix of loading both experience peel and shear stresses at the site of failure and thus the material response generated from the SLJ was applied directly to the anchor modelling.

The von Mises yield stress for the adhesive was defined initially at $17.2 \mathrm{MPa}$ as this was the maximum tensile strength provided by the company (see Table 5). In order to simulate the damage in the joint, a FORTRAN subroutine was implemented to take into account progressive damage based on the reduction of the yield stress. Fig. 19b shows the creep degradation scheme implemented. Once the equivalent creep strain, CEEQ [28] was greater than $90 \%$ of the maximum equivalent creep strain allowed, $C E E Q^{*}$, the yield stress, initially set at $17.2 \mathrm{MPa}$, was degraded linearly to $1 \mathrm{MPa}$, thus effectively producing local adhesive failure. Although in principle it might be possible to introduce this creep damage into a cohesive element as used in fatigue damage modelling discussed later, the continuum damage approach adopted here was simpler. As creep and fatigue damage have not been combined in the same analysis it seems reasonable to have different creep and fatigue damage models. 


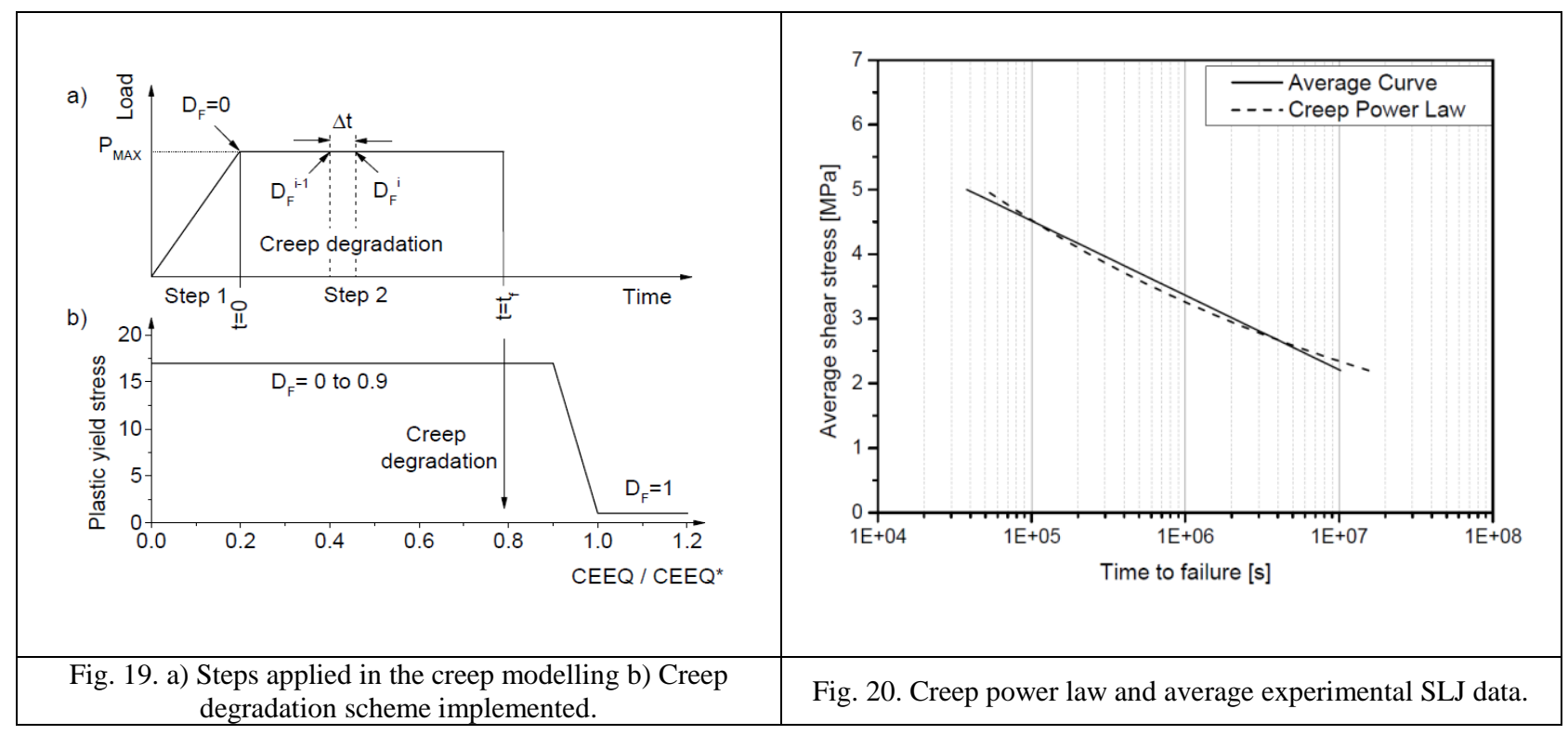

As the SLJ experimental campaign was not large enough to properly characterise both the first and second stage of creep, a simple power law creep response was used, which only modelled the (dominant) second stage. The power law is presented in Equation 1. The parameters of the power law are summarised in Table 6. It can be seen in Fig. 20 that the creep power law fits the average experimental stress-time to failure data (see also Fig. 6) very well.

$$
\begin{array}{|l|l|}
\hline \frac{d \varepsilon_{c r}}{d t}=A \cdot \sigma^{B} & (1) \\
\hline
\end{array}
$$

However, the maximum local equivalent creep strain $\left(C E E Q^{*}\right)$ in each geometry at failure was unknown. The maximum local equivalent creep strain was determined for each single lap joint geometry to obtain the failure time of the joint according to the power law. This was undertaken in an iterative manner, i) selecting a value of $C E E Q^{*}$, ii) using progressive damage FEA to determine the time to failure for that $C E E Q^{*}$, iii) adjusting the value of $C E E Q^{*}$ accordingly and repeating the process. The value of $C E E Q^{*}$ required was found to be adhesive thickness dependent. Fig. 21 shows the variation of $C E E Q^{*}$ as a function of the adhesive thickness (see Table 1). Although there is evidence in the literature for thickness dependent failure data such as fracture energy (attributed to changing sizes of plastic zone) the authors do not believe that the thickness is the main factor in determining these creep strains. Rather, they believe that this thickness dependent creep strain is mainly a result of having to represent the creep load-failure 
time by a single curve, Fig 6 . These data were used to determine the maximum equivalent creep strain allowed for the anchors with different thickness bondlines. The anchor thicknesses were 3, 4, 5 and $6 \mathrm{~mm}$ and the maximum allowable equivalent creep strain used in the creep modelling of the anchors were obtained as shown in Fig. 21.

Fig. 22 shows the creep strain distribution (normalised by the creep failure strain) at the point of failure for the SLJ with the thinnest adhesive layer. This is representative of the mode of failure in all the SLJs. The damage initiated at the ends of the joint and grew towards the centre on both interfaces. Both damage fronts were joined in the centre of the joint when they were adjacent to each other. When this occurred, the values of $C E E Q / C E E Q^{*}$ in red were greater than 0.9 and the joint was not able to carry the load specified because of the degradation of the plastic yield stress and thus failure was predicted.

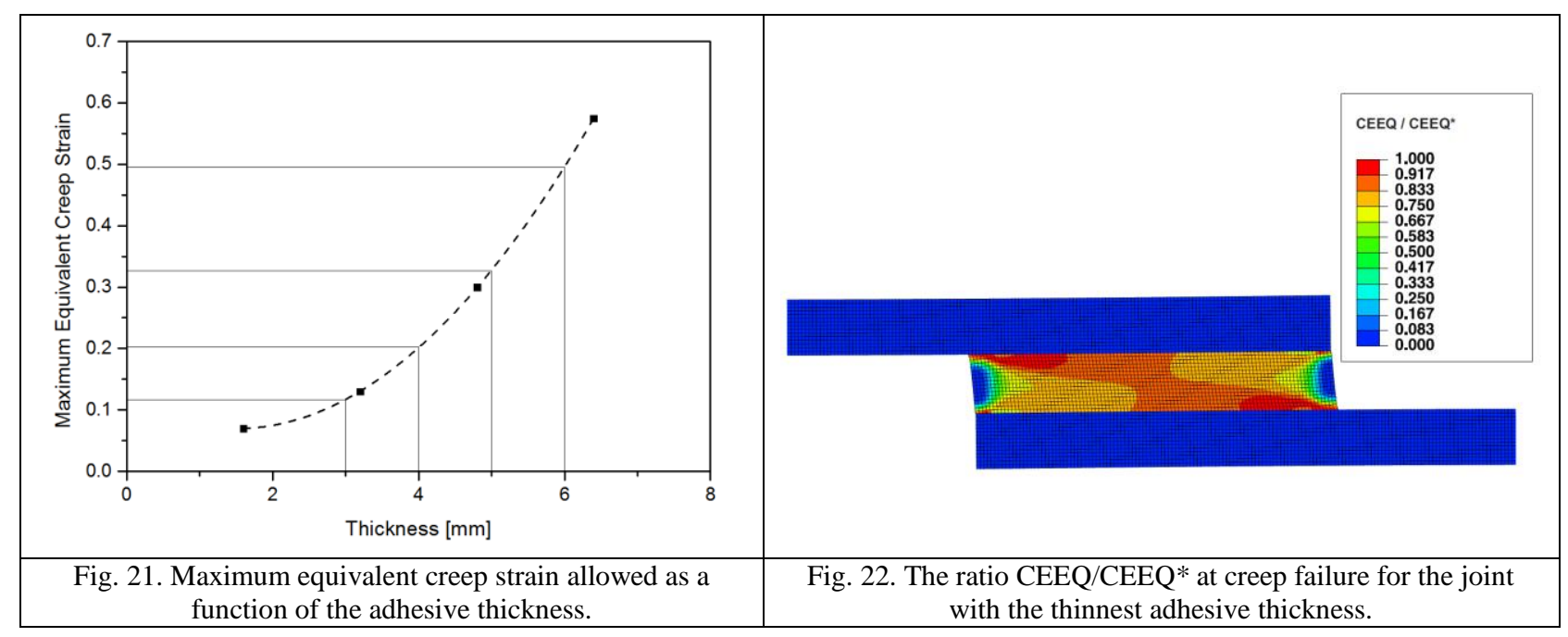

The anchors were modelled using the same power law as the SLJs. The maximum equivalent creep strain was determined according to the geometry of the anchor (see Fig. 21). In these models the creep time to failure was the unknown variable which was determined in the same way as in the SLJ (ie by the evolution of the localised creep failure). Thus, the anchors were modelled until the joint was no longer able to carry the load specified. The forces assessed were $24 \mathrm{kN}$ and $36 \mathrm{kN}$ (the mean fatigue loads) according to the Table 3. 
In the same way as the SLJs, the damage initiated at the top of the joint where stresses were highest and grew along the bonded interface towards the bottom. Fig. 23 shows the shear stress distribution at the last time increment of each anchor. The damage front travelled along the joint until it reached the bottom of the joint. At this point the joint was no longer able to carry the load and the failure of the anchor was assumed. It is worth mentioning that the damage front started to travel when the elements were not fully damaged. This means that these damaged elements still have some capacity to sustain load. This is perfectly reflected in the Fig. 23 where the lowest values of shear stress are about 3.0 MPa.

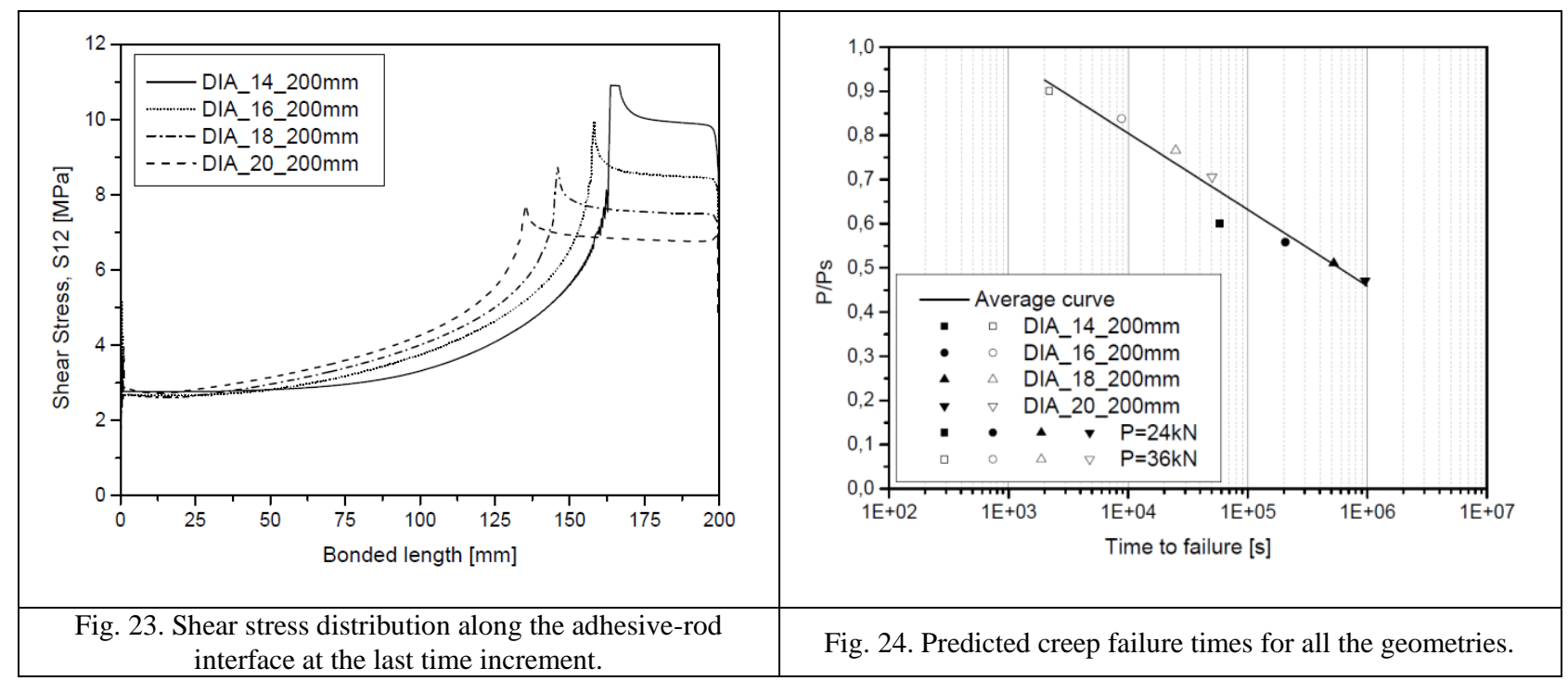

Fig. 24 and Table 7 show the predicted creep failure times for all the geometries at the two loads. In Fig. 24 the creep loads have been normalised by the static failure load of each anchor. The predicted creep failure time for each geometry fell on a unique curve showing a consistent trend. As can be seen in Table 7, for each geometry the predicted creep failure times were greater (by a factor ranging between 1.5 to 17.5 ) than the experimental fatigue tests. This suggests that in many of the cases considered creep may not significantly influence the fatigue experimental tests. Thus, the creep phenomenon was not considered in the subsequent fatigue modelling. This should be considered a starting point and subsequent research should address combining creep and fatigue damage. 


\begin{tabular}{|ccccc|}
\hline \multirow{2}{*}{ Specimens } & \multicolumn{2}{c}{ Time to failure at 24 kN } & \multicolumn{2}{c|}{ Time to failure at 36 kN } \\
\cline { 2 - 5 } & $\begin{array}{c}\text { Predicted creep } \\
\text { failure time [s] }\end{array}$ & $\begin{array}{c}\text { Longest experimental } \\
\text { fatigue test [s] }\end{array}$ & $\begin{array}{c}\text { Predicted creep } \\
\text { failure time [s] }\end{array}$ & $\begin{array}{c}\text { Longest experimental } \\
\text { fatigue test [s] }\end{array}$ \\
\hline DIA_14_200mm & 58,453 & 6,311 & 1,920 & 64 \\
DIA_16_200mm & 206,020 & 138,845 & 8,644 & 1,567 \\
DIA_18_200mm & 524,775 & 160,586 & 24,865 & 1,986 \\
DIA_20_200mm & 956,942 & 271,616 & 50,122 & 2,876 \\
\hline
\end{tabular}

It can be concluded from Fig. 24 and Table 7 that the adhesively bonded anchors for CFRP rods might suffer failure by creep at short values of time for high loads. This suggests the anchors should preferably be loaded at low loads so that creep phenomenon does not become a problem.

\subsection{Fatigue modelling}

Fatigue modelling of the anchors was undertaken using a progressive damage cohesive zone model (CZM) adjacent to the adhesive-rod interface. Von Mises plasticity was not considered in the adhesive material as the maximum tractions (see below) in the cohesive layer along the entire bond line essentially limited the maximum stress the remaining adhesive continuum. The constitutive behaviour of the cohesive element was defined by a traction-separation response. A quadratic interaction damage initiation criterion was used linking the tractions as outlined in Equation 2.

$$
\begin{array}{|l|l|}
\hline\left\{\frac{\left\langle t_{n}\right\rangle}{t_{n}^{0}}\right\}^{2}+\left\{\frac{t_{s}}{t_{s}^{0}}\right\}^{2}+\left\{\frac{t_{t}}{t_{t}^{0}}\right\}^{2}=1 & (2) \\
\hline
\end{array}
$$

Here, \langle\rangle is the Macaulay bracket means that the compression stress state does not contribute to damage initiation. The parameters $t_{n}, t_{s}$ and $t_{t}$ are the stress components predicted by the elastic traction-separation without damage and ${t_{n}}^{0}, t_{s}^{0}$ and $t_{t}^{0}$ are the nominal threshold stresses which specify the maximum traction allowed. The damage after the point of initiation was defined to increase with displacement up to complete failure at a critical value of displacement. The damage evolution is reduced through the expression proposed by Camanho and Davila (see Equation 3) [29].

$$
\begin{array}{|l|l|}
\hline D=\frac{\delta_{m}^{f} \cdot\left(\delta_{m}^{\max }-\delta_{m}^{o}\right)}{\mathrm{y}_{\boldsymbol{c}}} & (3) \\
\hline
\end{array}
$$




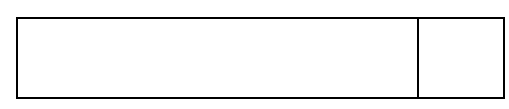

Here $\delta_{m}{ }^{m a x}$ refers to the maximum value of the effective displacement during each loading increment, $\delta_{m}{ }^{f}$ specifies the effective displacement at complete failure and $\delta_{m}{ }^{0}$ specifies the effective displacement at damage initiation.

A fatigue damage model was developed by Crocombe et al. [12] in which fatigue loading was defined by the maximum fatigue load, as shown in Fig. 25. The fatigue damage was simulated by degrading the cohesive properties defining the adhesive-rod interface using a fatigue damage evolution law. The initial normal and shear traction of the cohesive elements were established at 17.2 and 9.93 MPa, respectively. Once the damage initiated, the normal and shear traction were degraded linearly to 1.72 and $0.99 \mathrm{MPa}$, respectively. The maximum separation of the cohesive elements was defined by the effective displacement at $0.4 \mathrm{~mm}$, giving a mode I fracture energy of $3.45 \mathrm{kJm}^{-2}$. This value is not untypical for a toughened adhesive system and was used in the absence of any published data. Had a lower value been used, subsequent calibration to the fatigue response would have resulted in a different set of fatigue damage model parameters, discussed later. The fatigue damage evolution law is shown in Equation 4.

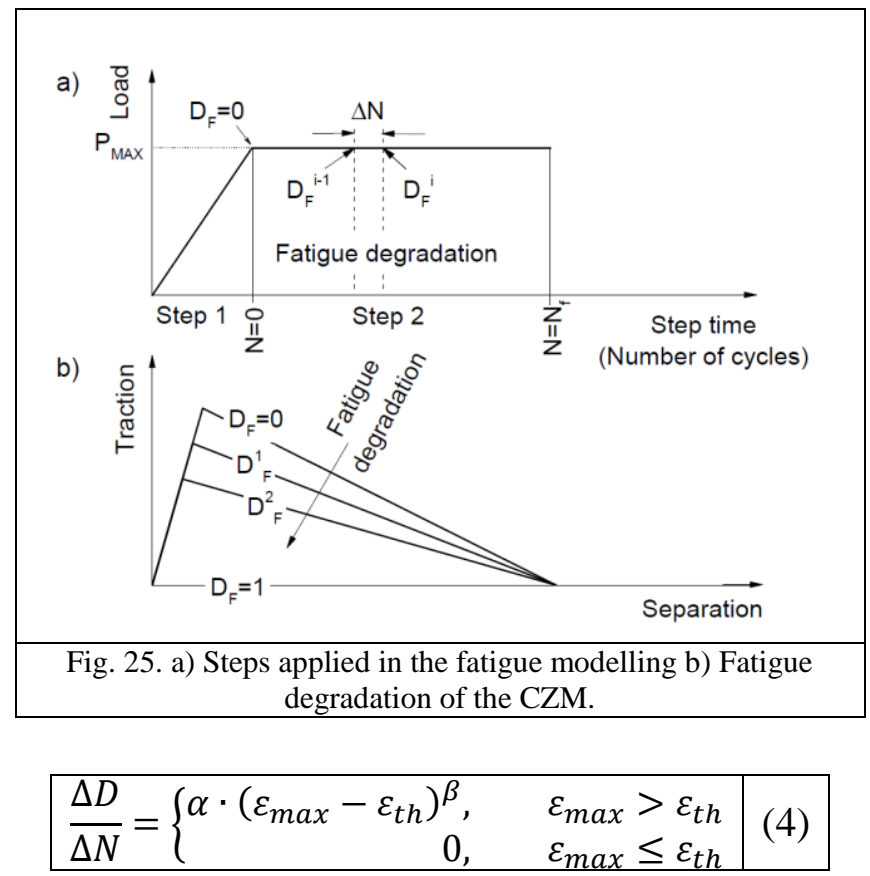




$$
\varepsilon_{\max }=\frac{\varepsilon_{n}}{2}+\sqrt{\left(\frac{\varepsilon_{n}}{2}\right)^{2}+\left(\frac{\varepsilon_{s}}{2}\right)^{2}}
$$

Here $\Delta D$ is the increment of damage and $\Delta N$ is the cycle increment. The parameters $\varepsilon_{n}$ and $\varepsilon_{s}$ are the averaged bond line normal and shear strains (the strain in the axisymmetric cohesive zone element is completely defined by these two components of strain). The parameter $\varepsilon_{\max }$ is a combination of these normal and shear strain components, $\mathcal{E}_{t h}$ is a threshold value which specifies the minimum strain to initiate the fatigue damage. The parameters $\alpha, \beta$ and $\varepsilon_{t h}$ are calibrated against the experimental results.

In this model, changing $\beta$ modifies the slope of the fatigue load-life $(P-N)$ curve, decelerating the damage evolution and increasing the lifetime when $\beta$ is increased, having a greater affect at higher strains (loads). Changing the constant $\alpha$ the P-N curve is shifted horizontally. When $\alpha$ is increased, the damage evolution is accelerated and the lifetime is reduced.

It is worth noting that the fatigue damage is a function of the number of cycles and the maximum principal strain, the latter depending on the maximum fatigue load applied. As the experimental fatigue results were found to be better correlated with the maximum fatigue load $\left(P_{\max }\right)$ than the load range $(\Delta P)$ (see Figs. 10 and 11), this load parameter was used in the modelling (see Fig. 25a). This formulation was used successfully by Crocombe et al. [12] and a simpler form of this was also utilised satisfactorily [13].

Fig. 25a shows the steps applied in the FE solution and Fig. 25b the fatigue degradation of the cohesive zone model. In the first step, the force was ramped linearly from 0 to $P_{\max }$ in 1 second. In the second step, the load remained constant until the joint failed. Three different levels of fatigue loading were modelled, following the experimental tests (see Table 3).

The progressive damage in the joint was incorporated using a FORTRAN subroutine and Fig. $25 \mathrm{~b}$ shows how the fatigue damage degraded the cohesive zone model parameters. For each increment of cycles $(\Delta N)$ and at every adhesive element integration point, Equation 4 was 
evaluated and the damage accumulated and stored. An iterative approach was undertaken to assess the effect of the fatigue damage model parameters on the fatigue response of the different geometries of the anchors. The fatigue damage model parameter values that matched the fatigue response of the anchors are summarised in Table 8.

\begin{tabular}{|c|c|c|}
\hline$\alpha$ & $\beta$ & $\varepsilon_{\mathrm{th}}$ \\
\hline 5,000 & 3.5 & 0.0225 \\
\hline
\end{tabular}

Like the creep analysis, stresses were initially highest at the end of the joint where the rod was loaded. When damage was initiated, the maximum stress moved down the adhesive-rod interface. As the damage front approached the bottom of the joint, the anchor was not able to carry the applied maximum load specified (see Table 3) and this was taken as the point of final fatigue failure. This is illustrated in Fig. 26 through four different stages of the damage front evolution and the corresponding shear stress distributions in the adhesive section for the anchor with the thinnest adhesive (DIA_14_200mm). This is representative of the mode of failure in all the anchors. Point "A" shows the shear stress distribution in the first fatigue cycle. At this point there is no damage in the bonded joint and so the joint behaves entirely linearly with the maximum stresses occurring at the top of the bonded joint. Once the damage is reached in the first elements of the cohesive layer, both damage front and maximum shear stress move down the bond line, as can be seen in the points "B", "C" and "D". Eventually, the bonded joint is not able to carry the maximum fatigue load applied and the fatigue failure is reached (point " $D$ "). 


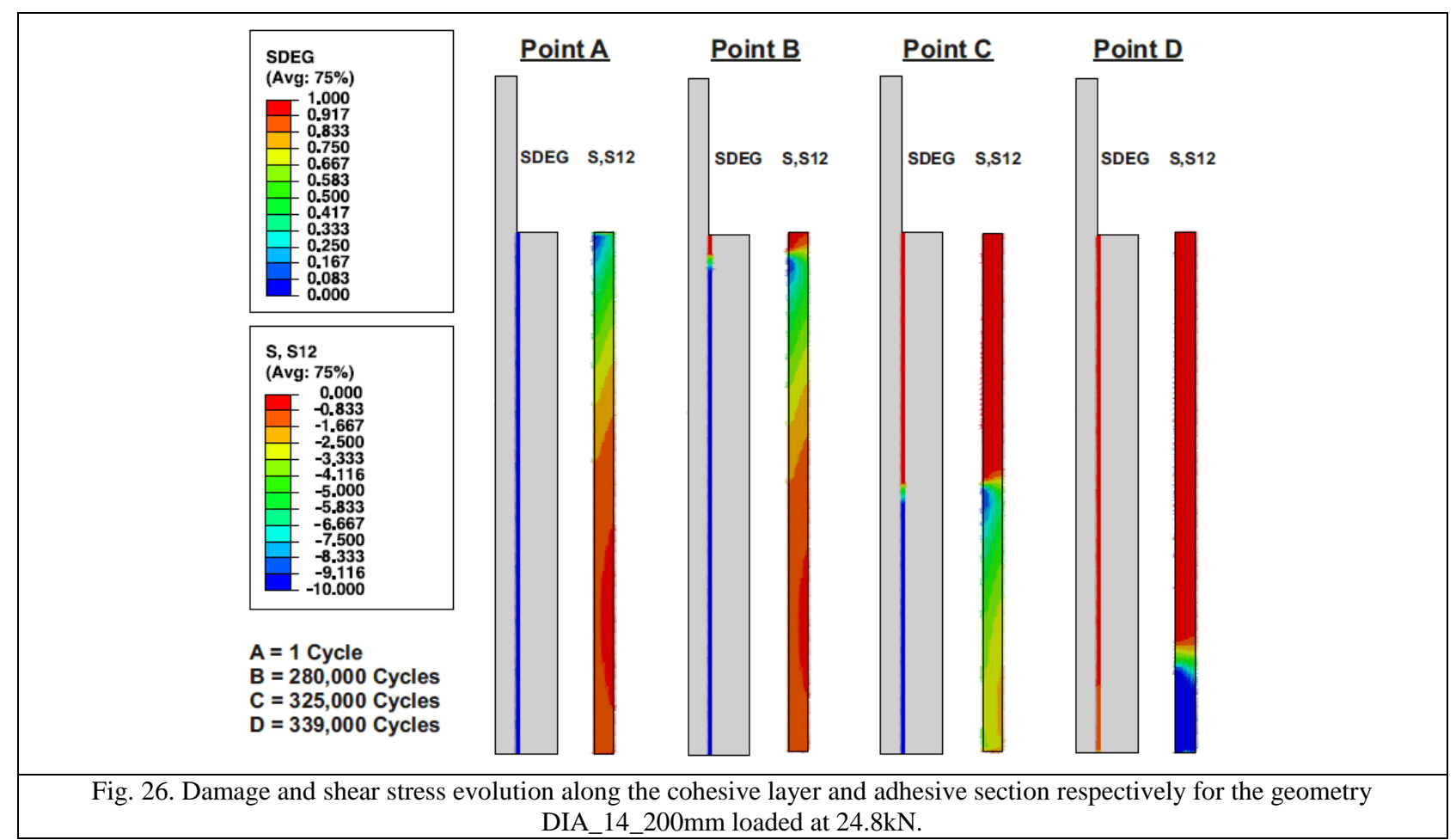

The predicted load-life data of each geometry correlated well with the experimental data, as shown in Fig. 27. Fig. 28 shows the results normalised by the experimental static load for each anchor configuration.

As mentioned in the experimental work, the predicted fatigue results showed that the anchors with a larger adhesive thickness reached a greater number of cycles to failure for the same level of load. An illustration of this can be seen in Fig. 27, where the non-normalised results are shown. However, as shown in Fig. 28, when the maximum fatigue load, $P_{\max }$, of the anchors, is normalised by the respective static failure load, the anchors with a thinner adhesive layer achieved higher number of cycles to failure for the same normalised load. Therefore, when the adhesive thickness was higher, the number of cycles to failure increased proportionally less than the static failure load.

As shown in Figs. 27 and 28, the proposed fatigue damage model for the anchors gave a consistent match with the experimental fatigue data in terms of life. This can provide confidence in the model in order to explore the fatigue life of other geometries and load cases. 


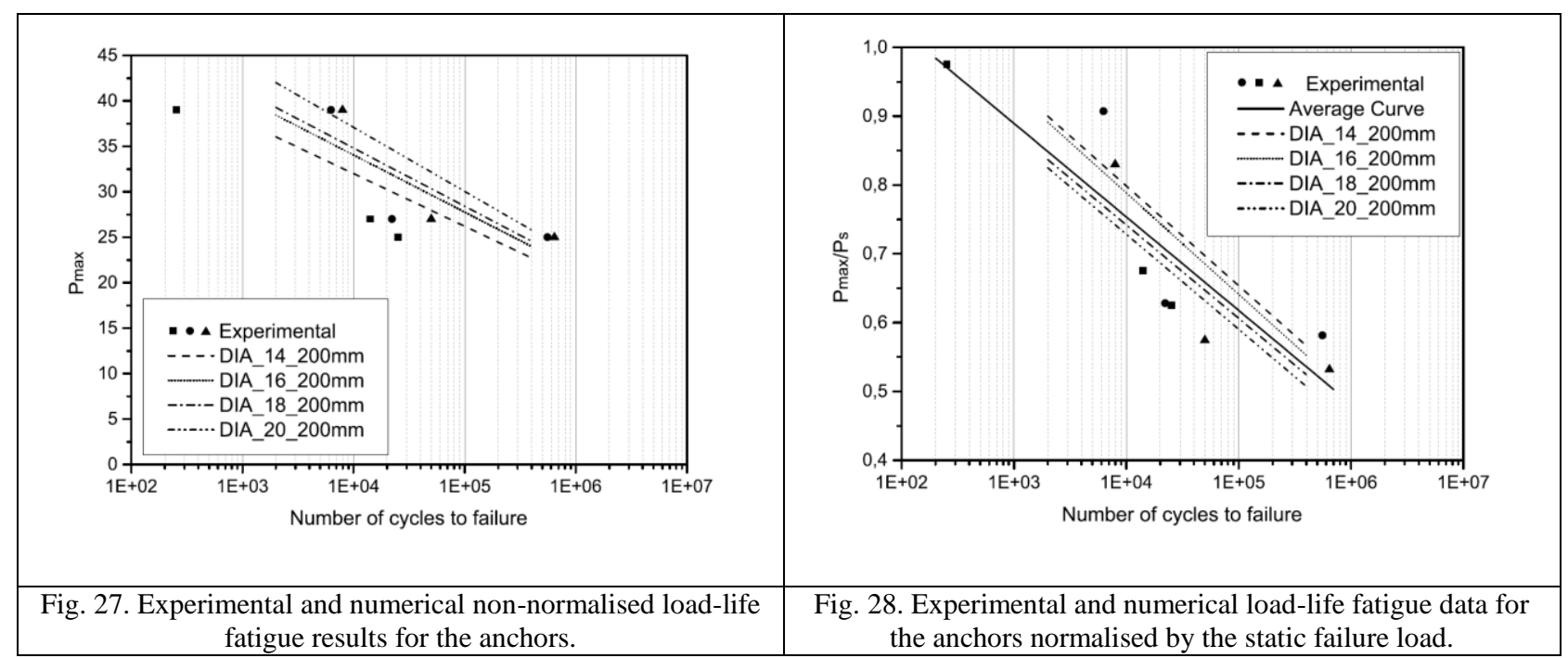

\section{Conclusions}

In this investigation, both creep and constant amplitude fatigue behaviour of adhesively bonded anchorages for CFRP tendons were investigated using both experimental and numerical approaches. Creep tests at different loads were conducted on SLJs of various geometries. The creep model, developed from the SLJs and applied to the anchors, was based on a rate-dependent analysis where the progressive damage and final creep failure were implemented by degrading the yield stress of the adhesive material. Regarding the creep analysis, the following conclusions can be drawn:

1. Creep tests conducted on the SLJs showed that specimens with thicker adhesive layers tended to have a shorter lifespan than specimens with thinner layers at the same creep load.

2. For the simple creep power law utilised in the numerical work the maximum equivalent creep strain in the SLJs at the failure load was thickness dependent.

3. Creep modelling of the anchors was undertaken successfully. This revealed that the lifespan of the anchors is short at high loads. This suggests that these anchors should be loaded at lower loads in order to increase their lifespan in real structures.

On the other hand, fatigue tests were undertaken on anchors with different load ratios, maximum fatigue loads and different adhesive thicknesses. The fatigue model was based on a cohesive 
zone model located along the adhesive-rod interface and controlled using a fatigue damage model. The following conclusions can be drawn:

4. Experimental fatigue results were more consistent when considering the maximum fatigue load than the loading range. If the static strength is known, the normalised results with the maximum fatigue load could be used to estimate the fatigue life of other configurations as a reasonably consistent normalised load-life curve was obtained.

5. The large predicted creep time to failure at the mean fatigue loads indicated that the creep loading aspect of the fatigue load should not significantly influence the fatigue lifetime in most of the joints considered. Thus, the influence of creep was not considered in the fatigue modelling.

6. The predicted fatigue results using a cohesive zone model with a fatigue damage evolution model were compared with the experimental results. It was found that the numerical model could successfully predict the fatigue life of the adhesively bonded anchors for CFRP rods.

7. It was observed experimentally and numerically that the anchors with thicker adhesive layers showed a higher number of cycles to failure at the same fatigue load. Nevertheless, for the same normalised fatigue load, anchors with thinner adhesive thickness were able to reach a greater number of cycles before failure.

\section{Acknowledgements}

The authors would like to thank the researcher Christian Escrig for his technical support during the experimental campaign. 


\section{References}

[1] Nanni A, Bakis CE, O’Neil EF, Dixon TO. Performance of FRP tendon anchor systems for prestessing concrete structures. PCI Journal 1996;Jan-Feb:34-44.

[2] Pincheira JA, Woyak J. Anchorage of Carbon Fiber Reinforced Polymer (CFRP) Tendons Using ColdSwaged Sleeves. PCI Journal 2001;Nov-Dec:100-11.

[3] Bahei-El-Din YA, Dvorak GJ. New designs of adhesive joints for thick composite laminates. Composites Science and Technology 2001;61:19-40.

[4] Puigvert F, Crocombe AD, Gil L. Static analysis of adhesively bonded anchorages for CFRP tendons. Construction and Building Materials 2014;61:206-15.

[5] Majó JAM. Estudio constitutivo de materiales compuestos laminados sometidos a cargas cíclicas. 2003.

[6] Ashcroft IA. Fatigue. In: Adams RD, editor. Adhesive bonding: Science, technology and applications, Woodhead publishing limited and CRC press LLC; 2005, p. 209-39.

[7] Crocombe AD, Richardson G. Assessing stress state and mean load effects on the fatigue response of adhesively bonded joints. International Journal of Adhesion and Adhesives 1999;19:19-27.

[8] Quaresimin M, Ricotta M. Life prediction of bonded joints in composite materials. International Journal of Fatigue 2006;28:1166-76.

[9] Lazzarin P, Quaresimin M, Ferro P. A two-term stress function approach to evaluate stress distributions in bonded joints of different geometries. The Journal of Strain Analysis for Engineering Design 2002;37:38598.

[10] Khoramishad H, Crocombe AD, Katnam KB, Ashcroft IA. Fatigue damage modelling of adhesively bonded joints under variable amplitude loading using a cohesive zone model. Engineering Fracture Mechanics 2011;78:3212-25.

[11] Khoramishad H, Crocombe AD, Katnam KB, Ashcroft IA. A generalised damage model for constant amplitude fatigue loading of adhesively bonded joints. International Journal of Adhesion and Adhesives 2010;30:513-21.

[12] Khoramishad H, Crocombe AD, Katnam KB, Ashcroft IA. Predicting fatigue damage in adhesively bonded joints using a cohesive zone model. International Journal of Fatigue 2010;32:1146-58.

[13] Graner Solana A, Crocombe AD, Ashcroft IA. Fatigue life and backface strain predictions in adhesively bonded joints. International Journal of Adhesion and Adhesives 2010;30:36-42.

[14] Gilbert CJ, Dauskardt RH, Ritchie RO. Microstructural mechanisms of cyclic propagation in grain-bridging ceramics. Ceramics International 1997;23:413-8.

[15] Xu G, Argon AS, Ortiz M. Nucleation of dislocations from crack tips under mixed mode of loading: implications for brittle against ductile behaviour of crystals. Philosophical Magazine A 1995;72:415-51.

[16] Maiti S, Geubelle PH. A cohesive model for fatigue failure of polymers. Engineering Fracture Mechanics 2005;72:691-708.

[17] Nguyen O, Repetto EA, Ortiz M, Radovitzky RA. A cohesive model of fatigue crack growth. International Journal of Fracture 2001;110:351-69. 
[18] Yamaguchi T, Kato Y, Nishimura T, Uomoto T. Creep rupture of FRP rods made of Aramid, Carbon and Glass fibers. Proceeding of the Non-metallic (FRP) reinforcement for concrete structures International symposium, 1997, p. 8.

[19] Da Silva LFM, Adams RD. Joint strength predictions for adhesive joints to be used over a wide temperature range. International Journal of Adhesion and Adhesives 2007;27:362-79.

[20] Melcher RJ, Johnson WS. Mode I fracture toughness of an adhesively bonded composite-composite joint in a cryogenic environment. Composites Science and Technology 2007;67:501-6.

[21] Su N, Mackie RI. Two-dimensional creep analysis of structural adhesive joints. International Journal of Adhesion and Adhesives 1993;13:33-40.

[22] BASF Construction Chemicals BS. MBrace Laminate - Product information. 2009.

[23] BASF Construction Chemicals BS. MBar Galileo - Product information. 2009.

[24] BASF Construction Chemicals BS. MBrace Primer - Product information. 2008.

[25] ASTM-D3165. Standard test method for strength properties of adhesives in shear by tension loading of Single-Lap-Joint laminated assemblies 2007;02:4.

[26] ASTM-D2294. Standard test method for creep properties of adhesives in shear by tension loading 2002;96:2.

[27] Findley WN, Lai JS, Onaran K. Creep and relaxation of nonlinear viscoelastic materials. Elsevier; 1989.

[28] Abaqus Analysis User Guide (v 6.13), Section 23.2.4 Rate-dependent plasticity: creep and swelling, Dassault Systemes, Paris

[29] Camanho PP, Dávila CG. Mixed-mode decohesion finite elements for the simulation of delamination in composite materials. NASA Langley Research Center, TM-2002-211737, 2002, p. 42. 